Flores, A., \& Scott, N. (2016). Destination, Tourism. In J. Jafari \& H. Xiao

(Eds.), Encyclopaedia of Tourism (pp. 1-4): Springer International Publishing.

\title{
Destination, tourism
}

From a geographic perspective, a destination is a particular place which a tourist plans to visit. Typically, natural and human attractions play a major role in making the choice (Gunn 1988). A destination is different from the tourist's normal environment. The term is used to describe locations at a range of scales from an individual resort, to a city, to a country or even a continent. A particular trip begins from an origin, through a transit region, to one or many destinations. It may be visited by tourists on a tour as a first stopover, as a hub for excursions, or as an exit point from a country. Tourists may be first timers or repeat visitors of a destination. The dispersal of tourists across destinations is important in determining their expenditure patterns. Stays may be restricted to an enclave resort area or travel around the core destination and beyond. The borders of a destination are often drawn based on political boundaries but arguably are better formulated from patterns of tourist behavior.

\section{Perspectives and elements}

Destinations are viewed from other disciplinary perspectives. For example, sociological studies stress that tourists create a destination through their patterns of displacement and consumption of the place (Framke 2002). The economic perspective focuses on the creation of value for tourists and the other stakeholders, implying the coordination of destination supply chain processes (Manente and Furlan 1998). From a management point of view, a destination is "a physical space in which a visitor spends at least one overnight. It includes tourism products such as support services and attractions, and tourism resources within one day's return travel time. It has physical and administrative boundaries defining its management, and images and perceptions defining its market competitiveness. Local destinations incorporate various stakeholders often including a host community, and can nest and network to form larger destinations” (UNWTO 2007:1).

From a management perspective, destinations are distinguished from places as they contain accommodation, attractions, hospitality services, shopping facilities, transportation services, and event facilities. This business cluster is organized around a set of tourism resources, including the environmental, historical and cultural heritage, and the ethnography 
and values of a host community. A destination is linked to its origin markets by a supply chain of wholesale or retail agents as well as through direct online booking systems. The distinct organization and authenticity of these resources give identity to the destination and allows tourists to have different experiences in different locations around the world.

Destinations are often described by their main attractions as "sun and sand”, cultural or historic, adventure, city, or countryside. Increasingly, destinations are developing more complex products and services that enhance their appeals or cater to new markets. Examples include tourism experiences related to health and medical services, conferences, conventions and events, and education or study opportunities. In addition, a destination may feature products such as surfing, gastronomy, skiing, golf, and the like. Transportation links are of importance in allowing tourists to access a destination. The historic growth of mass tourism to coastal destinations in England was based on new railway construction, and travel to Spain and Portugal was predicated on the development of commercial jet aviation. Low cost airlines have shifted demand to destinations near secondary airports.

Several models have sought to describe the characteristics, growth patterns, supply systems and demand for destinations, and their development or evolution has been a subject of much discussion. Destinations are considered to rise and fall in popularity over the longer term. Butler (1980) considered a destination develops through a number of stages to reach maturity and must ultimately face a choice between stagnation and renewal. Later models suggest destinations adopt evolutionary trajectories that are influenced by complex or chaotic factors.

\section{Marketing and management}

As destinations can geographically be remote from an origin, tourists are considered to have only imperfect limited knowledge or image of them, formed through sources including uncontrolled social media (organic image) and paid-for marketing (induced image). A destination's image is considered an important contributor to its attraction. Developing a marketing positioning and brand image is usually the role of a destination marketing organization. Ideally, the brand of a destination is supported by the community and business stakeholders and also provides a form of coordination among them. The Gold Coast is an Australian beach and sun destination that is popular with families. It has a number of other attractions such as theme parks and shopping. It is positioned as a fun destination and its brand image is based on the idea that it is "famous for fun”. While branding seeks to obtain a 
price premium for a trip to a destination, it is also important to be affordable to the target market and to provide a choice of accommodation and other facilities.

A tourist's choice of a destination is affected, among other factors, by seasonal amount of rain and sunshine, average temperature, and the timing of events and festivals. Seasonality may have a significant impact on business owners and residents with crowding during a peak in visitation and slow-down closure in the off-season. From a business and employment perspective, it is better to reduce such up and down variations over a year. Demand can be described in geographic terms using core and periphery or gravity models, and in psychological terms using push and pull factors. Tourists are attracted and spend most of their time in the core, but may visit attractions in the periphery. The distance to a destination is another important factor affecting profitability, with remote destinations generally less profitable. Attractions or facilities located in peripheral areas are considered to be disadvantaged in getting the volume. Push factors refer to psychological reasons for travel away from an origin, and pull factors refer to the perceived attraction of a destination. A number of more complex destination choice models have been developed (Becken and Gnoth 2004).

Destinations primarily contain numerous small businesses leading to claims that the tourism industry is fragmented and disorganized. To avoid this problem and to provide the coordination needed, many larger or more developed destinations appoint and fund an organization to be responsible for certain tasks. A destination marketing organization has the role of marketing the region while a destination management organization undertakes other functions such as planning or stimulation of innovation. It is common for a destination to prepare a tourism plan to guide its development. Collection of data about visitors is an important function of such organizations and the basis for planning. In the United States, such organizations are called convention and visitor bureaus, and are primarily funded by the private sector, while in Australia they may be called local or regional tourism organizations and receive partial government funding. At an international level, organizations such as the World Tourism Organization provide coordination among countries on issues such as training and improving destination access through easier visa processes. The aim of these organizations is to improve destination competitiveness to sustain tourism development.

In most destinations around the world, a destination marketing or management organization is embedded in a more or less hierarchical structure (Beritelli, Bieger and Laesser 2014). The local organizations are most often public-private partnerships in order to encourage strong cooperation and mutual sharing of benefits. Typically they are co-ordinated 
by a regional or state organization. In turn, there is normally one national tourism organization that provides a point of communication, coordination, and action for the whole industry in the country. Each of these organizations has roles that are sometimes overlapping, leading to issues of governance and efficiency. For example, a national tourism organization is responsible for promotion of a country overseas, but some larger destinations within the country may also wish to promote their destination leading to potential conflicts in the image being promoted and the need for marketing coordination. The identification and resolution of such organizational overlaps is an important source of increased efficiency in the management of tourism within a country.

\section{Destination sustainability}

Increasingly the effects of tourism on the fabric of a destination give rise to multiple types of impacts, including environmental, economic, social and cultural, leading to concerns over how destinations can be more sustainable, and thus maintain their competitiveness. This challenge has received attention from anthropologists, sociologists, environmentalists, among others. The effect of exceeding certain limits, usually measured in numbers of tourists is considered to lead to crowding and negative host-guest interactions. Similarly, exceeding environmental limits may lead to unacceptable changes in the natural setting of a destination. These impacts demand more attention from communities and government when considering the long term capacity of the destination to survive and reinvent itself, while contributing to the wellbeing of the host population.

Thus, new forms of governance and management of a destination are needed, such as networks, cluster development or local supply systems approaches. Sustainable plans manage the “impacts of tourism on the destination's environment, economy and community and maintains and enhances the destination's resources for the present and future needs of both tourists and the communities that host them” (UNWTO 2007:12). The effective sustainable management of destinations is an active area for research.

\section{Further research}

Destination is a central concept in tourism. It has been studied from a variety of perspectives, as is often found in the study of a multidisciplinary phenomenon such as tourism.

Destinations are in essence a microcosm of the larger world and hence are subject to similar trends and issues. Therefore, the topics relating to its study are continually changing. Recent issues of interest include the effect of crisis and disaster on a destination (Ritchie, Crotts, 
Zehrer and Volsky 2014) and conversely destination resilience. Increasingly, the concept of a destination product sold to a marketplace is being replaced by the idea of unusual experiences sought by tourists. While studies of such destinations as Antarctica, China, and Maldives are gaining popularity in academic circles, the subject in general is under-researched and hence under-developed (Prideaux 1996). It is even more so in respect to cross-cultural studies of emerging destinations, and stakeholders network analysis (Scott, Cooper and Baggio 2008).

See also: Destination lifecycle, destination marketing organization, destination branding, seasonality.

\section{References}

Becken, S., and J. Gnoth

2004 Tourist Consumption Systems Among Overseas Visitors: Reporting on American, German, and Australian Visitors to New Zealand. Tourism Management 25:375-385.

Beritelli, P., T. Bieger, and C. Laesser

2014 The New Frontiers of Destination Management: Applying Variable Geometry as a Function-based Approach. Journal of Travel Research 53:403-417.

Butler, R.

1980 The Concept of a Tourist Area Cycle of Evolution: Implications for Management of Resources. Canadian Geographer 24:7-14.

Framke, W.

2002 The Destination as a Concept: A Discussion of the Business-related Perspective Versus the Socio-cultural Approach in Tourism Theory. Scandinavian Journal of Hospitality and Tourism 2(2):92-108.

Gunn, C.

1988 Tourism Planning. New York: Taylor and Francis.

Manente, M., and M. Furlan

1998 Quality in the Macroeconomic System of Toruism. The Tourist Review 53(2):17-28.

Prideaux, B.

1996 The Tourism Crime Cycle: A Beach Destination Case Study. In Tourism, Crime and International Security Issues, A. Pizam and Y. Mansfeld, eds., pp.59-75. Chichester: Wiley. 
Ritchie, B., J. Crotts, A. Zehrer, and G. Volsky

2014 Understanding the Effects of a Tourism Crisis: The Impact of the BP Oil Spill on Regional Lodging Demand. Journal of Travel Research 53:12-25.

Scott, N., C. Cooper, and R. Baggio

2008 Destination Networks: Four Australian Cases. Annals of Tourism Research 35:169-188.

UNWTO

2007 A Practical Guide to Tourism Destination Management. Madrid: World Tourism Organization.

Adao Flores

University of Algarve, Portugal aflores@ualg.pt

Noel Scott

Griffith University, Australia

noel.scott@griffith.edu.au 